\title{
Compressive Strength of Uncured Concrete Cylinders Fully Wrapped with Post-Tensioned Metal Straps (PTMS).
}

DOI:10.36909/jer.13371

\author{
Serwan Khwrshid Rafiq ${ }^{1}{ }^{*}$, Wrya Abdullah $*^{2}$, Avesta Omar* ${ }^{3}$ \\ * Civil Engineering Department, University of Sulaimani, Sulaimani, Kurdistan Region, Iraq \\ ${ }^{1}$ Serwan.rafiq@univsul.edu.iq ; ${ }^{2}$ wrya.faraj@univsul.edu.iq; 3 Avesta.02000334@univsul.edu.iq
}

\begin{abstract}
During a national lock down and a curfew, most of the concrete projects are left without curing and therefore, the elements of the building need strengthening. An effective way in strengthening is using Post-Tensioned Metal Straps (PTMS) which is a relatively new method. Therefore, in this study, the effectiveness of using PTMS is tested in strengthening cylinder samples without curing. For this purpose, 15 cylinders are cast and 12 of them are left without curing for 28 days. Three samples are tested without any strengthening and are used as control samples. The rest are strengthened using 1, 2, 3, and full layers of PTMS. To compare the strength of the cylinders, 3 cylinders of the same batch are prepared and cured for 28 days. It is proved that the compressive strength of the cylinders can increase by $39 \%$, $57 \%, 84 \%$ and $125 \%$ if the samples are strengthened using 1, 2, 3, and full layers of PTMS. It is also found that the failure becomes ductile as the number of layers is increased.
\end{abstract}

Keywords: Cylinders, Curing, Post Tension Metal Strap (PTMS), Steel Strap (SS), Compressive Test. 


\section{INTRODUCTION}

Various reasons can cause a need for strengthening of existing reinforced concrete (RC) beams such as capacity loss of the elements which might take place due to material deterioration or sometimes due to emitting an essential procedure of curing the concrete. This might happen inevitably as in the case of a national lock down or curfew especially due to a pandemic such as a COVID-19 pandemic. Other cases that cause a loss in strength might take place after constructing the element for instance in case of increasing the loading, removing an element or adding a floor to the existing one. Some cases might be miscalculating the loads in both of the stage of design or construction (S. Altin, et al., 2005).

For elements resisting compressive stresses, confinement is a key in increasing the resistance otherwise the elements might fail abruptly. This is true in case of not having enough quantity of lateral reinforcement. Alternatively, the confinement might have been performed in a way that the spacing of the confinement is more than the one that is required by the standards. Leaving concrete without curing is another case in leading to produce a low quality of concrete, which its reason might be inevitable as in case of the total curfew.

Sudden change in loading such as earthquakes impose danger on the elements as they act laterally on the buildings (Zhou et al., 2019; Al-Maliki et al., 2021; Al-Soudani et al., 2021). For instance, during the 2017 earthquake of the border between Iraq and Iran, 500 people died as a consequence of collapsed buildings (W. Abdullah et al., 2021). The quake was regarded as the deadliest of the year as it had caused damage of 12000 buildings in the affected area (W. Abdullah et al., 2020).

Elements face premature failure in case of not providing confinement or providing a poor confinement. This can be prevented by the reinforcement of the elements and confining them either actively or passively. Therefore, the resistance can increase by providing confinement 
reinforcement in the element in forms of ties or stirrups. Confinement can also be performed externally as a strengthening of the elements after their construction.

To strengthen deficient elements, there are many methods to be used in the literature. Some of them are expensive, need a labour-intensive work and not durable. Therefore, Frangou et. al developed a method of using post tension metal strap in University of Sheffield (M. Frangou et al., 1995. The method is using the same heavy-duty metal straps that are usually used in packaging industry to confine the elements externally. It uses a pneumatic tensioner for the post tensioning. Numerous experimental works on using PTMS in strengthening elements and specimens can be found in the literature (C. Chin et al., 2018; C.L Chin 2019a; C.K. Ma et al., 2019; M. Chau-Khun et al., 2015; C.L.Chin et al., 2019b; Y. Helal, 2012; Y. Helal et al., 2016; Y. Yang et al., 2019; M. Setkit and T. Imjai, 2019; H. Moghaddam et al., 2010). Some of the researchers worked on enhancing the strength of full-scale elements (Mongabure, P., \& Tamaris, 2012). While a few of them worked on shear strength improvement in concrete beams after exposing them to fire (Y. Yang et al., 2019). M. Setkit and T. Imjai (2019) used PTMS to strengthen the beams that failed in bending. However, strengthening cylinders using PTMS for uncured samples is very rare to find in the literature. Therefore, carrying out research on using PTMS in strengthening normal concrete is necessary especially after the COVID-19 pandemic where there is a possibility of announcing a curfew without warning.

\section{EXPERIMENTAL PROGRAMME}

In total fifteen cylinders are cast and tested for compressive strength. The cylinder has a diameter of $150 \mathrm{~mm}$ and a height of $300 \mathrm{~mm}$. The standard steel mould is used. The testing is performed under standard conditions and at the load rate of $0.2 \mathrm{MPa} / \mathrm{sec}$. The samples are left in their moulds for 30 days without curing and then tested under the machine. To compare the 
results, three samples of the similar batch are made and tested after 28 days of being immersed under water.

\subsection{General Material Properties:}

Apart from the metal straps and the strapping machines, all the other materials are locally available in Sulaymaniyah governorate in Kurdistan region of Iraq.

\subsubsection{Cement}

The cement was Ordinary Portland Cement with IQS 5-CEM I 42.5 R. Fresh cement out of the company's storage was used to avoid having other weak points in the tests.

\subsubsection{Coarse and fine aggregate tests}

First, the coarse aggregate is a mixture of the natural and crushed stones. The maximum size of the coarse aggregate is selected to be $10 \mathrm{~mm}$ and the mix design is performed based on that size. The sieve analyses of both fine and coarse aggregates are compared with the ranges set by ASTM C33-92 and comply with it.

The fine aggregate is naturally available from river. The maximum size of the fine aggregate is $4.75 \mathrm{~mm}$. The fineness modulus of the sand was 3.31 .

\subsubsection{Metal Straps}

For the purpose of strengthening, metal straps are used which are like the belts but are made from metal. The material was bought from China in rolls. It is used in the packaging industry categorized under heavy duty metal straps. The width of the used sample is $31.75 \mathrm{~mm}$ and the thickness is $0.8 \mathrm{~mm}$, giving a cross-sectional area of $25.4 \mathrm{~mm}^{2}$. An example of the metal strap with the clip for clipping is shown in Figure 1 (a). Aluminium clips are bought to secure the joint of the two ends of the strap. The metal straps have a yielding strength of 928 . The modulus of elasticity of the strap is found to be $237 \mathrm{GPa}$. The load- strain curve of the tested 
samples is shown in Figure 1 (b). The behaviour of the material is elastic- perfectly plastic because the strain increases with the increasing stress until it reaches the yield strength and then it will stay there for an elongation of $9 \%$ and then breaks. Figure 1 (b) shows that the behaviour is like the steel rebars as the machine used for testing it was built to test only rebars.

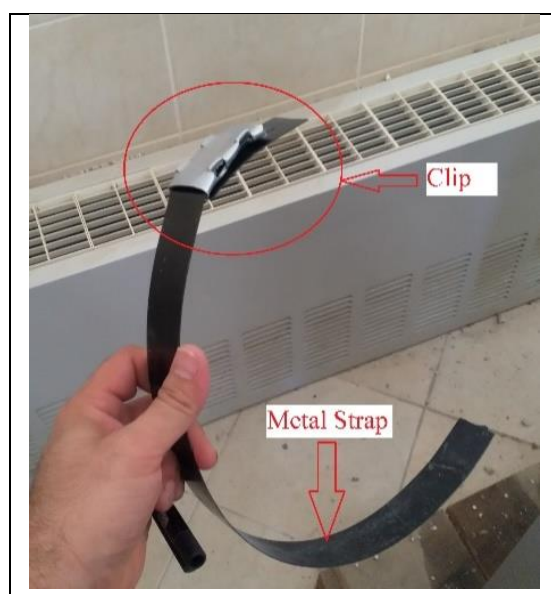

(a) Metal strap and the clip

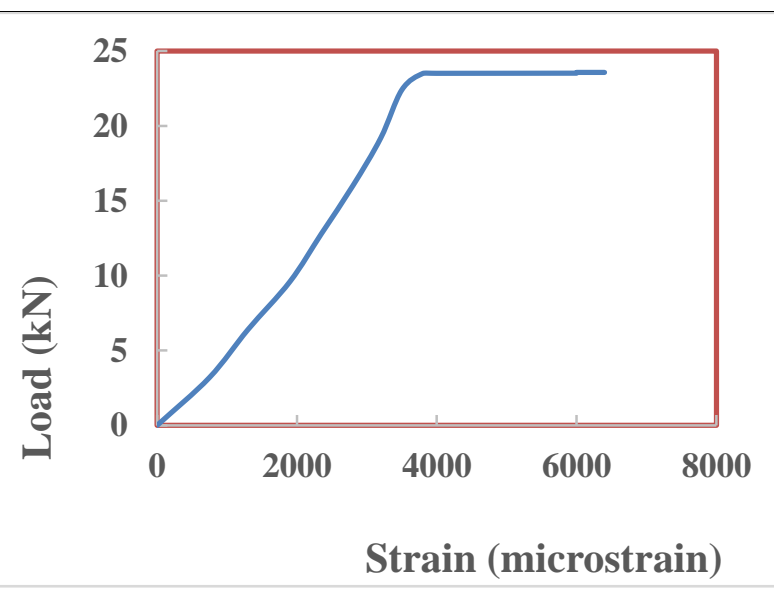

(b) Load - strain curve of the metal strap

Figure 1: Metal strap with its clip and four notches, with load- strain curve.

\subsection{Materials and specimen fabrication}

The target of the mix design is to achieve a compressive concrete strength of $25 \mathrm{MPa}$. For that purpose, the concrete mix was designed based on ACI 211.1-91. Based on the design, the mixing ratio of 1:2.02:2.384 is used between cement, coarse aggregate, and fine aggregate. Also, the water to cement ratio is selected to be 0.61 . Table 1 shows the mix proportions of the concrete. All the samples are cast on the same day. During casting a slump cone test is performed to measure the slump of the concrete which is found to be $110 \mathrm{~mm}$. After casting the concrete, the samples are left in their moulds for 28 days without curing apart from those three samples that are left for comparison. A set of three samples without curing are tested to work like control sample. The configuration of the metal strap is kept as the variable.

Table 1: Mass of the ingredients of the concrete 


\begin{tabular}{|c|c|c|c|c|}
\hline \multirow{2}{*}{ Water $(\mathrm{kg})$} & $\begin{array}{c}\text { Cement } \\
(\mathrm{kg})\end{array}$ & Coarse & $\begin{array}{c}\text { Fine aggregate } \\
\text { aggregate }(\mathrm{kg})\end{array}$ & Total $(\mathrm{kg})$ \\
\hline 255 & 380 & 769 & 907 & 2311 \\
\hline
\end{tabular}

\subsection{Strengthening}

Metal straps are used for strengthening. The way it is used is like buckling up a belt. First, a desired length of the strap is cut from the roll using an angle grinder. Then, an aluminium clip is put in one of the ends of the straps to the length of $110 \mathrm{~mm}$. Then that length is manually bent to lock the clip in its place. After that, the free end of the straps is wrapped around the cylindrical concrete until it comes back to the clip. Thus, the free end now is put back in the clip for the second time making a knot as shown in Figure 2 (a). Now is the time of using pneumatic tensioner shown in Figure 2 (b).

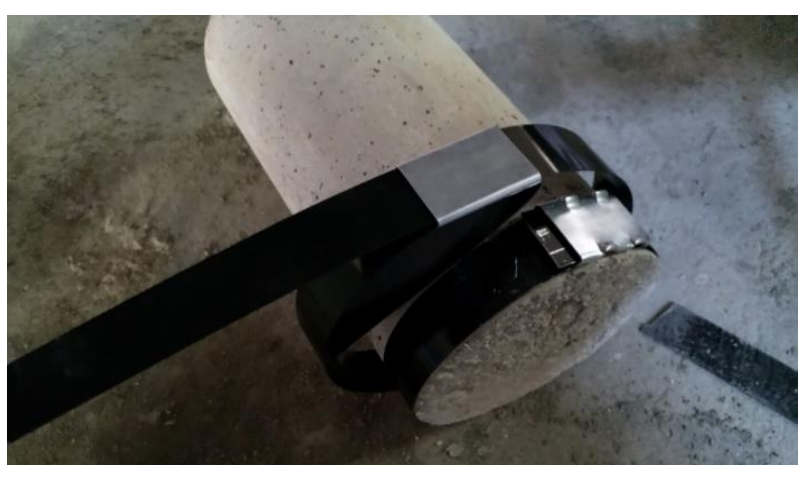

(a) Procedure of strapping

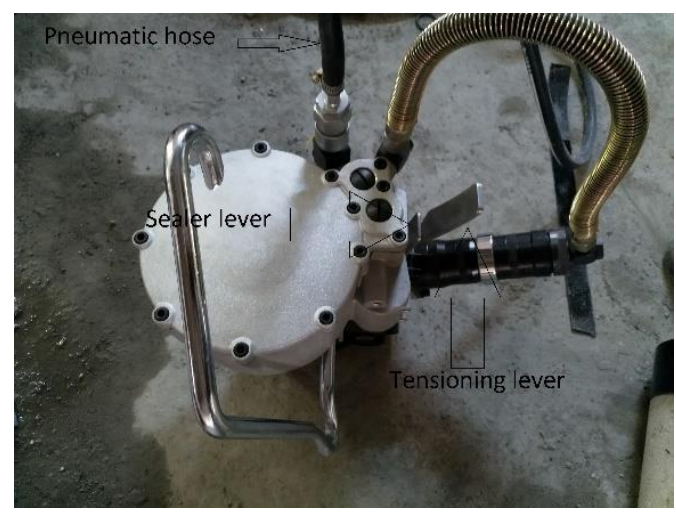

(b) Metal tensioner

Figure 2: Strengthening procedure using PTMS

The tensioner consists of the two parts needed in post tensioning which are the tensioner and the sealer. The tensioner is usually used for tensioning the straps. After tensioning the straps to the desired tension, the sealer part can be operated by pressing the lever marked in Figure 2 (b). The machine is called KZ-32 strap packing tool commercially. The locking force of the 
machine is approximately $18.4 \mathrm{kN}$. Both of the pneumatic tensioner and sealer are running on an air compressor.

When the sealer is used, the jaws of the machine bites the clip and creates four notches which makes it strong enough to have relaxation in it. Moghaddam et al. proved that no relaxation takes place in a sample tensioned for two months. They also proved that the amount of the tension on the samples is adequate to strengthen them actively which is estimated to be $30 \%$ of the total yield strength of the material. In terms of stretching without rupturing the material can be elongated to $9 \%$ in $30 \mathrm{~mm}$ of its length which complies with ASTM D3953. It worth mentioning that the size of the strap is $31.75 \mathrm{~mm}$ in width and its thickness is $0.8 \mathrm{~mm}$ so the jaws of the machine is made to house this type of the strap otherwise a different type of machine should be used based on the width of the strap. Also, the clips are made in a way that they can house the width of the strap so they must be ordered correctly, otherwise it might not be able to deliver the task. Apart from the control samples, all the other samples are strengthened using four layers of PTMS on top and bottom edges of the concrete cylinder to avoid having a weak point in the cylinders then the strengthening is provided in layers of one, two, three and fully wrapped, as shown in Figure 3.

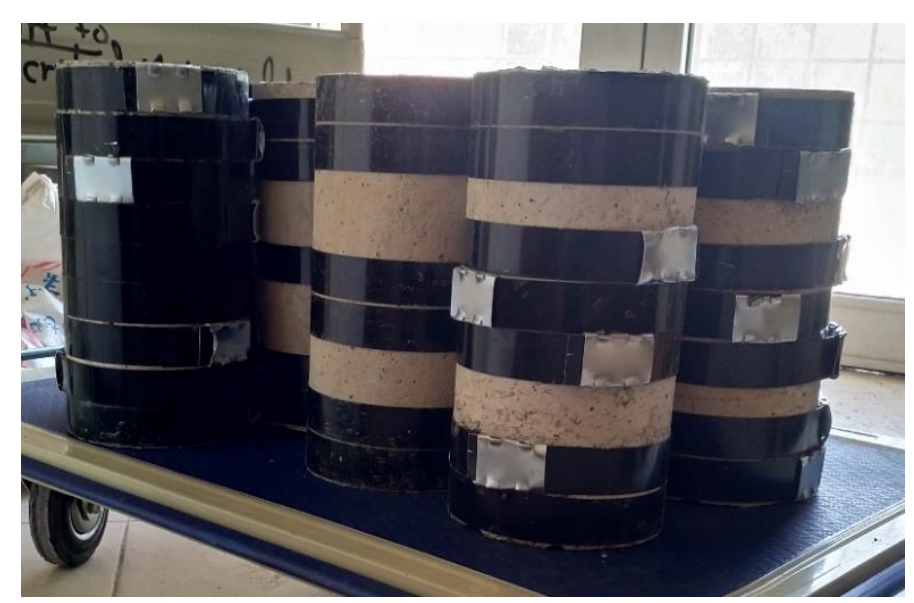

Figure 3: Samples after strapping 


\subsection{Equipment setup and testing procedure}

A machine from Control Company has been used to test the samples for compression. The load rating of $0.2 \mathrm{MPa}$ per second is used for the tests. Before testing the samples, the capping process is performed using gypsum plaster with a ratio of 2:1 for gypsum to water.

\subsection{Cylinder samples}

All the sample labels and their description are shown in Table 2.

Table 2: Sample numbers and descriptions

\begin{tabular}{|c|c|c|}
\hline Sample description & Curing status & Beam \\
\hline Control Sample & Not cured & 3 \\
\hline Sample strengthened using one layer of PTMS & Not cured & 3 \\
Sample strengthened using two layers of PTMS & Not cured & 3 \\
Sample strengthened using three layers of PTMS & Not cured & 3 \\
Sample strengthened using full layers of PTMS & Not cured & 3 \\
\hline Not strengthened & Cured \\
\hline
\end{tabular}

\section{RESULTS AND DISCUSSION}

\subsection{Effects of PTMS}

Table 3 shows all compressive strengths and the percentages of increase of the compressive strength based on the type of strengthening. The average compressive strength of the control sample is 20.37 MPa. Using one layer of PTMS can increase the compressive strength of the concrete by $39 \%$. However, this rate of increase decreases to $18 \%$ if the number of layers 
increased from one to two. It is evident that with an increase of number of layers the compressive strength is increasing, therefore, by increasing the number of layers to three from two, the rate of increase in the compressive strength of the concrete is $27 \%$. It is obvious that this rate has reached its peak once the samples are fully wrapped with PTMS as the rate of increase is $41 \%$. If compared with the control samples, the compressive strength of the fully wrapped samples has increased by $125 \%$ which is more than the double of the compressive strength of the control samples.

Table 3: External strain gauges on control sample.

\begin{tabular}{|c|c|c|c|c|c|}
\hline Sample & $\mathbf{1}$ & $\mathbf{2}$ & $\mathbf{3}$ & Average & Percent \\
\hline Control & 18.11 & 20.94 & 22.07 & 20.37 & \\
sample & 25.41 & 30.91 & 28.9 & 28.41 & $39 \%$ \\
1 Layer & 34.17 & 30.25 & 31.7 & 32.04 & $57 \%$ \\
2 Layers & 38.65 & 36.31 & 37.5 & 37.49 & $84 \%$ \\
3 Layers & 45.00 & 46.6 & 45.8 & 45.8 & $125 \%$ \\
Cured & 26.65 & 28.93 & 26.55 & 27.38 & $34 \%$ \\
concrete & & & & & \\
\hline
\end{tabular}

Figure 4(a) and (b) show the compressive strength of the samples. The compressive strength of the samples increases linearly with an increase in the number of layers so an equation is derived to predict the compressive strength with the number of the layers used in strengthening. 


$$
y=5 x+20
$$

In the equation $y$ is the compressive strength in $\mathrm{MPa}$ and $x$ is the number of layers used in strengthening of the concrete. The base of that equation is $20 \mathrm{MPa}$ which has underestimated the compressive strength of the concrete. The equation underestimates the results for all the layers. As for the full wrapped case, only five layers were enough to achieve full wrapping. Therefore, if number 5 is put in the equation, the result comes out to be $45 \mathrm{MPa}$ which is very close to the what is achieved during the tests.

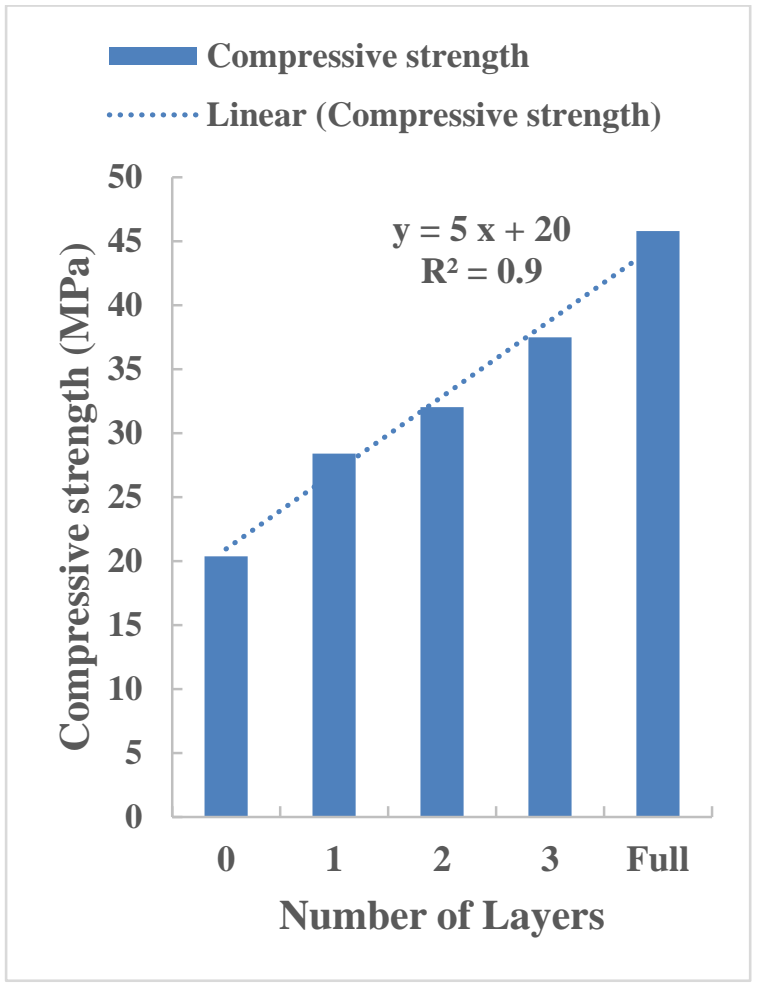

(a) Compressive strength of the samples

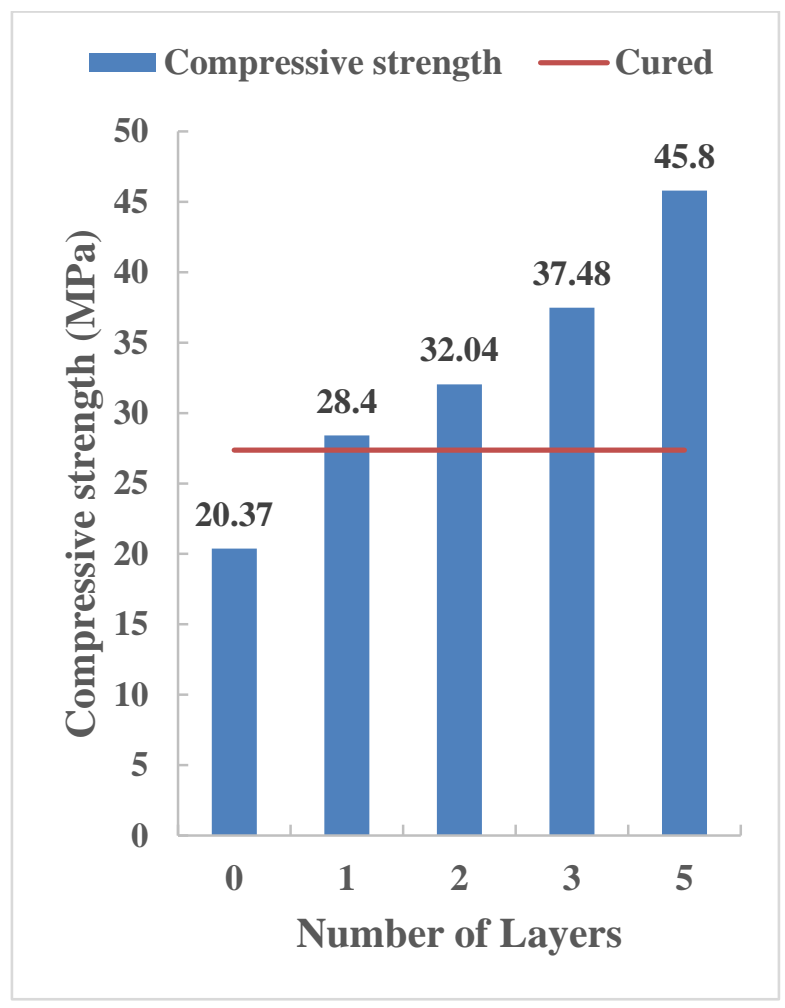

(b) Comparison between the samples

Figure 4: Compressive strengths of the samples wrapped with different layers of PTMS

\subsection{Effects of curing}

If the cured samples are to be compared with the ones without curing, it can be noticed that curing can increase the compressive strength of the samples by $34 \%$ on average. Also, it is observed that the difference between the trials for concrete without curing is substantial as 
there is a $4 \mathrm{MPa}$ difference between two groups of the samples. This proves that the concrete without curing is inconsistent.

\subsection{Effects of PTMS on the cured sample.}

In Figure 4 (b), it is obvious that by providing only one layer of PTMS the strength of the concrete can be more than that of the cured samples by $4 \%$. This rate of enhancement, rises by increasing the number of layers to two which will be $17 \%$. This rate will reach $37 \%$ if the number of the layers increased to three. Finally, $67 \%$ can be noticed if the samples strengthened with PTMS fully wrapped around the cylinder compared with the cured samples.

\subsection{Crack pattern}

The failure mode of the concrete shows that the concrete is squeezed by the PTMS and it is fully confined actively. In Figure 5 (a), the concrete portions pop out between the straps looking like a curtain, which points to the failure in the unconfined parts. The failures of the PTMS happened right at the edge of the clip as shown in Figure 5(b), creating a sound like the sound of rupturing steel bars during tensile strength test.

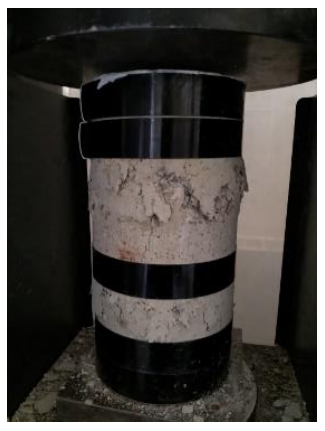

(a) Crack pattern

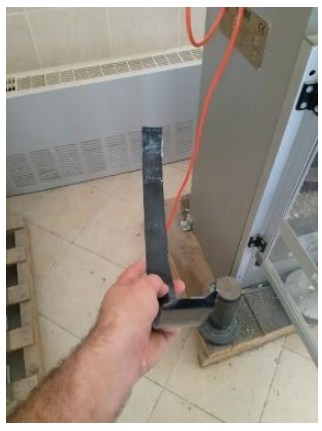

(b) Strap failure point

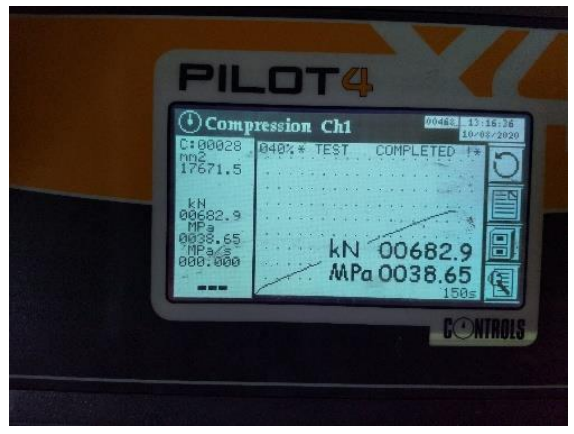

(c) Ductility of strengthened sample

Figure 5: (a) crack pattern, (b) strap failure and (c) ductility of the sample with PTMS. 


\subsection{Ductility of the samples}

It is noticed that during the tests, the concrete failed in a ductile manner without having any internal reinforcement which proves that by using this method of strengthening a ductile behaviour can be achieved for samples even without providing any reinforcement. The result appeared on the testing machine screen of the sample strengthened with three layers is shown in the Figure 5 (c).

\section{Conclusions}

In this research study concrete samples without curing are strengthened using post-tension metal straps (PTMS). The following conclusions can be drawn:

1. During curfew and a total lock down, concrete elements cannot be cured, which may cause a loss in their strength and therefore, strengthening is needed.

2. There is a strength scatter in between the compressive strength of the concrete samples that are not cured which reaches $4 \mathrm{MPa}$ of strength due to their inconsistent drying surface of the concrete.

3. The compressive strength of the concrete can increase significantly by using PTMS for strengthening the samples. These increases count for $39 \%, 57 \%, 84 \%$, and $125 \%$ if the samples are strengthened with one, two, three, and five (or wrapped fully with) layers of PTMS, respectively.

4. The compressive strength of the uncured samples strengthened with PTMS is more than that of the cured samples by $4 \%, 17 \%, 37 \%$ and $67 \%$ if the samples are to be strengthened with one, two, three, and five (or wrapped fully with) layers of PTMS, respectively. 
5. The failure of the samples shows evidence on PTMS actively confining the concrete as parts of the concrete are popping out in between the layers of PTMS as the concrete underneath the straps are squeezed and confined.

6. The failure will be more ductile and the toughness of the concrete samples increases with an increase in number of layers of PTMS.

\section{$\underline{\text { References }}$}

S. Altin, Ö. Anil, and M. E. Kara (2005). Improving shear capacity of existing RC beams using external bonding of steel plates. Eng. Struct., vol. 27, no. 5, pp. 781-791. doi: 10.1016/j.engstruct.2004.12.012.

Zhou, J., Fang, X., \& Jiang, Y. (2019). Comparison of the earthquake responses of superhigh-rise building structures based on different seismic design spectra. Journal of Engineering Research (Kuwait), 7(4), 58-80.

Al-Maliki, A., Mohammed, M. S., Al-Soudani, M., \& Husein, H. N. (2021). Examination of Anchorage of Mesh Wire on Seismic Response of Infilled Walls in RC Frames. Journal of Engineering Research, 1-20. https://doi.org/10.36909/jer.10413

Al-Soudani, M., Abbas, A. N., \& Numan, H. A. (2021). Assessment of Reinforced Concrete Structures under Wind and Earthquake Using Different Design Methods. Journal of Engineering Research, 1-21. https://doi.org/10.36909/jer.10411

W. Abdullah, S. Rafiq, and Y. Alshkane (2021). Reflections of Halabjah Earthquake effects on the structural building damages in Halabjah and Darbandikhan. J. Univ. Dhok, vol. 23, no. January, pp. 321-341. 
W. Abdullah, S. K. Rafiq, and Y. M. Alshkane (2020). Severity of damage due to 2017 Kurdistan Region of Iraq-Iran border earthquake (Halabja Earthquake). IOP Conf. Ser. Mater. Sci. Eng., vol. 978, no. 1. doi: 10.1088/1757-899X/978/1/012017.

M. Frangou, K. Pilakoutas, and Dritsos S. (1995). Structural repair/strengthening of RC columns. Constr. Build. Mater., vol. 9, no. 5, pp. 1-8.

C. Chin, C.-K. Ma, A. Z. Awang, W. Omar, and A. B. H. Kueh (2018). Stress-strain evaluation of steel-strapped high-strength concrete with modified self-regulating end clips. Struct. Concr., vol. 19, no. 4, pp. 1036-1048. doi: 10.1002/suco.201700134..

C. L. Chin, C. K. Ma, J. Y. Tan, C. B. Ong, A. Z. Awang, and W. Omar (2019a). Review on development of external steel-confined concrete. Constr. Build. Mater., vol. 211, pp. 919-931. doi: 10.1016/j.conbuildmat.2019.03.295.

C. K. Ma, R. Garcia, S. C. S. Yung, A. Z. Awang, W. Omar, and K. Pilakoutas (2019). Strengthening of pre-damaged concrete cylinders using post-tensioned steel straps. Proc. Inst. Civ. Eng. Struct. Build., vol. 172, no. 10, pp. 703-711. doi: 10.1680/jstbu.18.00031.

M. Chau-Khun, A. Z. Awang, W. Omar, K. Pilakoutas, M. M. Tahir, and R. Garcia (2015). Elastic design of slender high-strength RC circular columns confined with external tensioned steel straps. Adv. Struct. Eng., vol. 18, no. 9, pp. 1487-1499. doi: 10.1260/1369-4332.18.9.1487.

C. L. Chin, C. K. Ma, A. Z. Awang, J. Y. Tan, C. B. Ong, and W. Omar (2019b). Confining stress path dependent stress-strain model for pre-tensioned steel-confined concrete. Eng. Struct., vol. 201, no. April, p. 109769. doi: 10.1016/j.engstruct.2019.109769. 
Y. Helal (2012). Seismic Strengthening of Deficient Exterior RC Beam-Column Subassemblages using Post- tensioned Metal Strips. PhD thesis, The University of Sheffield.

Y. Helal, R. Garcia, K. Pilakoutas, M. Guadagnini, and I. Hajirasouliha (2016). Strengthening of short splices in RC beams using Post-Tensioned Metal Straps. Mater. Struct. Constr., vol. 49, no. 1-2, pp. 133-147. doi: 10.1617/s11527-014-0481-6.

Y. Yang, S. Feng, Y. Xue, Y. Yu, H. Wang, and Y. Chen(2019). Experimental study on shear behavior of fire-damaged reinforced concrete T-beams retrofitted with prestressed steel straps. Constr. Build. Mater., vol. 209, pp. 644-654. doi:

10.1016/j.conbuildmat.2019.03.054.

M. Setkit and T. Imjai (2019). Strengthening performance of damaged concrete beams in service conditions using post-tensioned metal strapping technique. J. King Mongkut's Univ. Technol. North Bangkok, vol. 29, no. 4, pp. 577-584. doi: 10.14416/j.kmutnb.2019.09.004.

H. Moghaddam, M. Samadi, K. Pilakoutas, and S. Mohebbi (2010). Axial compressive behavior of concrete actively confined by metal strips; Part A: Experimental study. Mater. Struct. Constr., vol. 43, no. 10, pp. 1369-1381. doi: 10.1617/s11527-0109588-6.

Mongabure, P., \& Tamaris. (2012). BANDIT Seismic Strengthening of Deficient RC Buildings Using Ductile Post - Tensioned Metal Strips. Seventh Framework Programme: Capacities Specific Programme Research Infrastructures Project (227887). 